\title{
A prospective study on the incidence of rheumatoid arthritis among people with persistent increase of rheumatoid factor
}

\author{
H D Halldórsdóttir, T Jónsson, J Thorsteinsson, H Valdimarsson
}

\begin{abstract}
Objectives-To study the stability of rheumatoid factor (RF) increases and to compare the incidence of rheumatoid arthritis (RA) in people with transient or persistent increase of one or more RF isotypes.

Methods-From an original cohort of nearly 14000 participants in a population study, 135 previously RF positive persons were recruited in 1996 and evaluated according to the 1987 ACR criteria. The observation time ranged from 9-22 years (mean 16.5). Blood samples were obtained from all participants at entry and again in 1996.

Results-About $40 \%$ of the participants who had only one raised RF isotype in the original sample had become RF negative in 1996 compared with only $15 \%$ of those with increase of two or three RF isotypes $(p=0.002)$. The seven participants who developed RA during the study period all had persistently raised RF. Six of the 54 participants with more than one RF isotype raised in 1996 developed RA, corresponding to an annual incidence of $0.67 \%$, which was 7.5 times higher than observed in the other participants $(\mathrm{p}=0.045)$.

Conclusion-Symptom free persons with persistently raised RF have greatly increased risk of developing RA. This suggests that dysregulation of RF production is a predisposing factor in RA.

(Ann Rheum Dis 2000;59:149-151)
\end{abstract}

Rheumatoid factor (RF) may play an important part in normal immune responses ${ }^{1}$ and increased RF is occasionally found in apparently healthy people. Increased concentration of $\mathrm{RF}$ is found in most rheumatoid arthritis (RA) patients although it can also be increased in other rheumatic diseases and in infections. However, a combined increase of $\operatorname{IgA}$ and $\operatorname{IgM}$ $\mathrm{RF}$ is almost exclusively found in RA and has therefore a high diagnostic specificity for this disease. ${ }^{2}$ Population surveys have shown that the majority of people with increased RF do not have symptoms of rheumatic diseases or chronic infections. ${ }^{3}$ The role of $\mathrm{RF}$ in the pathogenesis of RA is therefore not clear, and reports are lacking on the stability of increased $\mathrm{RF}$ isotypes and the risk of symptom free people with persistenly raised RF to develop RA. However, increase of RF has been found to precede clinical symptoms of RA and the prerheumatoid $\mathrm{RF}$ isotype patterns have been similar to those observed in established disease. $^{34}$

Aho et al have estimated that the prevalence of seropositive arthritis in Finland is approximately $0.5 \%$ in men and $1.1 \%$ in women, increasing progressively from the age of 30 to 69 years, whereafter it seemed to level off. ${ }^{4}$ Reports from other countries have shown an overall prevalence of approximately $1 \% .^{5}$ The annual incidence of RA in adult white populations has been reported to lie between 0.022 and $0.06 \%$ in different studies. ${ }^{67}$ We have previously reported that symptom free people with raised RF have increased risk of developing RA compared with matched RF negative controls. ${ }^{3}$ This paper reports a serological and clinical follow up on the previously seropositive participants of this study with an average observation time of 16.5 years.

\section{Methods}

STUDY BACKGROUND

A prospective health survey has been conducted in the Reykjavík area by The Icelandic Heart Association since November 1967. Collection of data relating to rheumatic diseases and RF started in 1968 and the original study design has been described. ${ }^{3}$ Briefly, the participants were born between 1907 and 1935 and selected randomly from all inhabitants in the Reykjavík area of Iceland. Between 1974 and 1983 a total of 16299 blood samples were collected from 13858 participants who were all evaluated for symptoms of rheumatic diseases. These blood samples were tested for RF by the Rheumaton agglutination slide test, and positive samples were tested further by the Rose-Waaler (RW) technique. All samples with a RW titre of $1 / 10$ or more were measured for IgM, IgG and IgA RF isotypes by ELISA. ${ }^{8}$ The participants were considered seropositive if they had two or more RF isotypes above the $95 \%$ cut off as determined by 200 randomly selected age matched controls. Participants with two RF isotypes under the $95 \%$ cut off level were only included if their third RF isotype was above the $97.5 \%$ cut off level. ${ }^{3}$

In 1987 all available RF positive participants $(n=173)$ and age and sex matched RF negative participants $(n=156)$ were evaluated clinically and new blood samples collected. None of the $156 \mathrm{RF}$ negative controls from the 1987 study were included in this study.

SELECTION OF PARTICIPANTS FOR EVALUATION IN 1996

In addition to the $173 \mathrm{RF}$ positive participants in the 1987 study, 46 people who had been RF 
Table 1 Stability of increased $R F$ isotypes and prevalence of $R A$ during the follow up period $^{\star}$

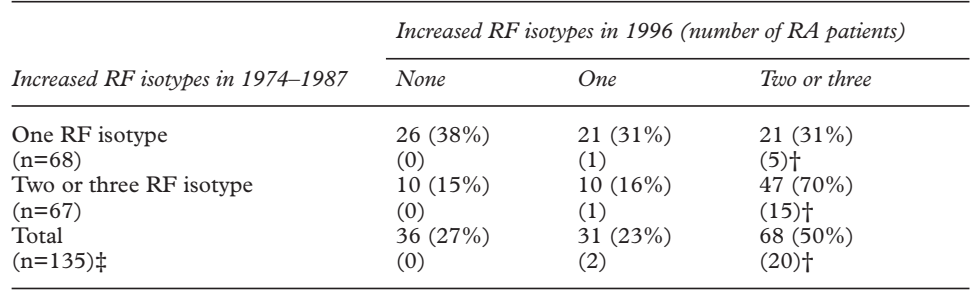

*Numbers in parentheses show the 22 RA patients in relation to past and present RF findings. $\dagger$ All these RA patients had an increase of both IgM and IgA RF. $¥ 115$ of these 135 people participated in the 1987 study and 20 had been RF positive in the original sample but could not be recruited to the study in 1987. Thus, only previously RF positive people were included in this study.

positive in the original blood sample but could not be recruited to the study in 1987 were considered eligible for this study. Of these 219 persons 52 had died in 1996. Of the 167 that were thus potentially available $135(81 \%)$ could be recruited to this study, including 115 of the 173 seropositive participants from 1987 and 20 people who had previously been RF positive by agglutination and ELISA but were unable to participate in the 1987 study. The remaining 32 had either moved from the Reykjavik area or could not be traced. The participants, 62 men and 73 women, were all evaluated by structured interview and physical examination according to the American College of Rheumatism (ACR) criteria from $1987^{9}$ without knowledge of previous clinical or RF findings, and new blood samples were collected. Thus, at least two blood samples from each participant, taken at an interval of 9-22 years (mean 16.5) were tested for RF isotypes. It should be noted that before $1987 \mathrm{RF}$ had been measured only by agglutination in a few of the participants. Thus, their isotypes were first measured in 1987. As the incidence of RA was evaluated in the context of RA isotypes in this study, an observation time of only nine years could be taken into account for these people.

Table 2 Incidence of $R A$ in relation to $R F$ findings in original blood samples from 1974-1987

\begin{tabular}{|c|c|c|c|}
\hline \multirow[b]{2}{*}{ Increased $R F$ isotypes in original blood samples } & \multicolumn{3}{|c|}{ Development of $R A$ during the study period } \\
\hline & Number & $\begin{array}{l}\text { Follow up } \\
\text { period } \\
\text { (mean) }\end{array}$ & $\begin{array}{l}\text { Annual } \\
\text { incidence (\%) }\end{array}$ \\
\hline One $R F$ isotype $(n=64)$ & $2(3.1 \%)^{\star}$ & 15.6 & 0.20 \\
\hline Two or three RF istotypes $(n=56)$ & $5(8.9 \%) \dagger$ & 17.7 & 0.50 \\
\hline Total $(n=120)$ & $7(5.8 \%)$ & 16.5 & 0.35 \\
\hline
\end{tabular}

${ }^{\star}$ One of these two patients had both IgM and IgA RF raised in his 1996 sample. †Four of these patients had combined increase of IgM and IgA RF.

Table 3 Incidence of $R A$ and RF findings in blood samples from 1996

\begin{tabular}{|c|c|c|c|}
\hline \multirow[b]{2}{*}{ Increased $R F$ isotypes in 1996 blood sample } & \multicolumn{3}{|c|}{ Development of $R A$ during the study period } \\
\hline & Number & $\begin{array}{l}\text { Follow up } \\
\text { period } \\
\text { (mean) }\end{array}$ & $\begin{array}{l}\text { Annual incidence } \\
\text { (95\% confidence } \\
\text { intervals) } \neq\end{array}$ \\
\hline Group 1: No RF isotype $(n=36)$ & $0(0 \%)$ & 16.1 & $0 \%(0,0.6)$ \\
\hline Group 2: One RF isotype $(n=30)$ & $\star_{1}(3.3 \%)$ & 16.8 & $0.2 \%(0.01,1.04)$ \\
\hline Group 3: Two or three $\mathrm{RF}$ istotypes $(\mathrm{n}=54)$ & †6 $(11.1 \%)$ & 16.7 & $0.67 \%(0.25,1.36)$ \\
\hline
\end{tabular}

Group 1 versus groups 2 and 3: $\mathrm{p}=0.074$. Groups 1 and 2 versus group 3: $\mathrm{p}=0.045 .{ }^{\star}$ Isolated $\operatorname{IgM}$ RF. †Five of these patients had two or three isotypes increased in the original blood sample. $¥$ The approximate annual RA incidence and $95 \%$ confidence intervals in Finnish adults ( $\geqslant 16$ years) was $0.029(0.025,0.032){ }^{6}$
MEASUREMENT OF RF

The ELISA for IgM, IgG and IgA RF has been described in detail elsewhere. ${ }^{8}$ The sera were tested at a dilution of $1 / 40$ against a serial dilution of a local standard that had been calibrated against an International Reference Preparation (Statens Serum Institut, Copenhagen). Aggregated rabbit IgG was used to block any free IgG binding site on the solid phase bound RF. Two RF positive control sera were included in each test batch to monitor assay variability, which was about $10 \%$.

In $1996 \mathrm{RF}$ values above the upper $95 \%$ cut off level ( $\geqslant 25 \mathrm{AU} / \mathrm{ml}$ ) for 200 normal subjects were considered increased for each RF isotype.

\section{STATISTICAL ANALYSIS}

The results were analysed by the $\chi^{2}$ test, or Fisher's exact test when appropriate. The level of significance was set at $\mathrm{p}<0.05$.

\section{Results}

STABILITY OF RF INCREASES

Of the 67 participants with two or three RF isotypes increased in the original sample 47 $(70 \%)$ still had two or more raised RF isotypes 9 to 22 years later, and only $10(15 \%)$ had become seronegative (table 1). In contrast, of the 68 participants who had only one isotype raised $(97.5 \%$ cut off) in the original sample 26 (38\%) were seronegative ( $95 \%$ cut off) in 1996 $(\mathrm{p}=0.002)$. Of the individual isotypes IgG RF was less stable than IgM or IgA RF. However, $21(31 \%)$ of the single positives had developed an additional isotype increase and of these five were diagnosed with RA (table 1). There was not a significant association between RF stability and age of the participants. It should be noted that the 22 patients with RA all had persistently raised RF, 16 had an increase of more than one RF isotype in the original blood sample, and 20 had more than one RF isotype increased in 1996, involving in all cases a combined increase of IgM and IgA RF. Thus, the prevalence of RA was $16 \%$ in the whole group compared with $29 \%$ among participants with increase of more than one RF isotype.

RA INCIDENCE AND RF STABILITY

Of the 135 participants, 15 had manifestations of RA when the original blood samples were collected in 1974-1987. As can be seen from table 2 seven of the 120 symptom free seropositive participants developed RA during the observation period, which ranged from 9 to 22 years (mean 16.5), corresponding to an average annual incidence rate of $0.35 \%$. However, none of the 36 participants who became seronegative developed RA and only one of 30 with persistently raised single RF isotype, compared with six of 54 with an increase of more than one RF isotype (table 3). The risk of developing RA was thus about 7.5 times greater in the last group than among the remaining participants $(p=0.045)$. It should be noted that symptoms of RF did not begin in any of the seven participants until at least two years after the original blood sample was obtained. Furthermore, none of the participants had a history of symptoms 
suggesting that they might have developed a transient RA that had subsided when this study was carried out.

\section{Discussion}

In this study the long term stability of RF isotype increases was evaluated in the context of prevalence of RA and the risk of developing this disease. In agreement with previous studies $^{3}$ increase of RF was very stable $(100 \%)$ in the RA patients, but it was also relatively stable in participants who had still not developed RA, especially in those with a combined increase of IgM and IgA RF (74\%).

The prevalence of RA has been estimated to be approximately $1 \%$ among white populations ${ }^{5}$ but it was $16 \%$ in our RF positive study cohort. It is of interest that participants with increased concentrations of both $\operatorname{IgM}$ and IgA RF in 1996 had about 10 times higher prevalence of RA than those who had become seronegative or had only one persistently increased RF istotype (table 1). This agrees with the finding that $\operatorname{IgM}$ and IgA RF is characteristic for RA patients. ${ }^{210}$ Eberhardt et al have reported similiar RF isotype increases in early $\mathrm{RA}^{11}$ and divergent findings may in part be attributable to methodological differences. ${ }^{12}$

Increase of RF before clinical onset of RA is well documented. ${ }^{312} 13$ The annual incidence rate of RA has in several studies been reported to be $0.022 \%$ to $0.06 \%,{ }^{74}$ and in Finland the annual incidence of seropositive RA was estimated to be about $0.03 \%$ between 1980 and $1990 .{ }^{6}$ We have previously reported that about $5 \%$ of 173 symptom free subjects with increased RF developed RA during a mean observation time of 9.6 years compared with none of 156 age and sex matched RF negative controls. ${ }^{3}$ Our present findings indicate that people with an increase of more than one RF isotype have an annual RA incidence of $0.67 \%$, which is about 22 times higher than was observed for RF positive RA in the adult Finish population between 1980 and $1990 .{ }^{6}$ Furthermore, epidemiological studies have shown an annual incidence rates ranging from 0.074 to 0.157 for people over 40 years. ${ }^{14}$ However, the mean age at diagnosis of RA increased from 50.2 to 57.8 years between 1975 and $1990 .{ }^{15} \mathrm{It}$ is not known whether this also applies to Iceland.
In conclusion, our findings show that an increase of RF is relatively stable even in symptom free persons, especially when more than one RF isotype is raised. Furthermore, symptom free people with stable increase of RF have a markedly increased incidence of RA, the predominant $\mathrm{RF}$ pattern being a combined increase in IgM and IgA RF. The fact that increases of RF can precede clinical disease for a long period of time indicates that factors regulating $\mathrm{RF}$ production may play a primary part in the pathogenesis of RA.

We thank Drs Ásmundur Brekkan and Nikulás Sigfússon for their contribution to this study.

Funding: this study was funded by The Icelandic Science Foundation and the National Hospital Science Fund.

1 Solty AJ, Axford JS, Sutton BJ. Rheumatoid factors: where are we now? Ann Rheum Dis 1997;56:285-6.

2 Jónsson Th, Steinsson K, Jónsson H, Geirsson ÁJ, Thorsteinsson J, Valdimarsson H. Combined elevation of IgM and IgA rheumatoid factors has very high diagnostic specificity for rheumatoid arthritis. Rheumatol Int 1998; 18:119-22.

3 Jónsson T, Thorsteinsson J, Kolbeinsson A, Jónasdóttir E, Sigfússon N, Valdimarsson H. Population study of the mportance of rheumotoid factor isotypes in adults. Ann Rheum Dis 1992;51:863-8.

4 Aho K, Heliövaara M, Maatela J, Tuomi T, Palosuo T. Rheumatoid factor antedating clinical rheumatoid arthritis. Rheumatol 1991;18:1282-4.

5 Spector TD. Rheumatoid arthritis. Epidemiol Rheum Dis $1990 ; 16: 513-37$.

6 Kaipiainen-Seppänen $\mathrm{O}$, Aho $\mathrm{K}$, Isomäki $\mathrm{H}$, Laakso $\mathrm{M}$. Incidence of rheumatoid arthritis in Finland during 19801990. Ann Rheum Dis 1996;55:608-11.

7 Chan K-WA, Felson DT, Yood RA, Walker AM. Incidence of rheumatoid arthritis in central Massachusetts. Arthritis Rheum 1993;36:1691-6.

8 Jónsson T, Árnason JA, Valdimarsson H. Enzyme-linked immunosorbent assay (ELISA) screening test for detection of rheumatoid factor. Rheumatol Int 1986;6:199-204

9 Arnett FC, Edworthy SM, Bloch DA, McShane DJ, Fries JF, Cooper NS, et al. The American Rheumatism Association 1987 revised criteria for the classification of rheumatoid arthritis. Arthritis Rheum 1988;31:315-24.

10 Swedler W, Wallman J, Froelich C, Teodorescu M. Routine measurement of IgM, IgG and IgA rheumatoid factors: high sensitivity, specificity, and predictive value for rheumatoid arthritis. J Rheumatol 1997;24:1037-43.

11 Eberhardt KB, Svenson B, Truedsson L, Wollheim FA. The occurrence of rheumatoid factor isotypes in early definite rheumatoid arthritis-No relationship with erosions or disease activity. J Rheumatol 1988;15:1070-4.

12 Aho K, Palosuo T, Raunio V, Puska P, Aromaa A, Salonen JT. When does rheumatoid disease start? Arthritis Rheum 1985;28:485-9.

13 Toumi T, Palosuo $\mathrm{T}$, Aho $\mathrm{K}$. The distribution of class-specific rheumatoid actors is similar in rheumatoid and pre-illness sera. Scand J Immunol 1986;24:751-4.

14 Linos A, Worthington JW, O'Fallon WM, Kurland LT. The epidemiology of rheumatoid arthritis in Rochester, Minnesota: a study of incidence, prevalence and mortality. Am J Epidemiol 1980;111:87-98.

15 Kaipiainen-Seppänen O, Aho K, Isomäki, Laakso M. Shift in the incidence of rheumatoid arthritis toward elderly patients in Finland during 1975-1990. Clin Exp Rheumatol $1996 ; 14: 537-42$. 